\title{
GERAÇÃO DE ENERGIA EÓLICA USANDO A PLATAFORMA LABVIEW
}

DOI: 10.37702/2175-957X.COBENGE.2021.3424

Stefânia Oliveira Silva - sosilva4@gmail.com

Universidade Federal do Oeste da Bahia

Rua do Machado 81

47600-000 - Bom Jesus da Lapa - BA

Resumo: Este artigo, tem como propósito apresentar alguns potenciais aplicações do software LabVIEW da National Instruments, como ferramenta de aprendizagem prática desassociado do laboratório físico, aplicado em experiências ligadas à área de sistemas de energia elétrica como ferramenta de apoio ao ensino remoto na geração eólica. É sabido que o processo de geração de energia através de aerogeradores é complexo, dado seus componentes e como interagem no conjunto, apresentando as vantagens e desvantagens deste meio de geração. Com o auxílio o LabVIEW, foram obtidos dados do vento e mensura da velocidade do vento por meio de sua modelagem. Este programa possibilita o acesso à montagem experimental do minissistema de energia pelo computador instalado na bancada do laboratório, permitindo também aos alunos, o monitoramento e controle do experimento a partir de seus próprios computadores, visualizando e reforçando no laboratório, os conceitos vistos na teoria.

Palavras-chave: vento, turbina eólica, coeficiente de potência, energia renovável 


\section{GERAÇÃO DE ENERGIA EÓLICA USANDO A PLATAFORMA LABVIEW}

\section{INTRODUÇÃO}

Diversos autores destacam a importância das atividades laboratoriais para assimilação de conceitos abstratos, percepção da realidade, compreensão dos fenômenos físicos, de forma que aumente a capacidade do aluno aplicar os conhecimentos obtidos em aulas teóricas. As práticas, além de facilitarem a fixação do conteúdo, favorecem a conexão entre o conhecimento empírico com o conhecimento científico (MORAIS et al., 2014).

Normalmente, as atividades de disciplinas de experimentação são realizadas em laboratórios que possuem instrumentos tradicionais, como osciloscópios, geradores de sinais e multímetros (AGILENT TECHNOLOGIES, 2012). Entretanto, esses mesmos laboratórios implicam em altos custos para as instituições, tanto na implantação quanto na sua manutenção, sendo que geralmente são necessários lugares apropriados para armazenamento desses instrumentos e instrutores para gerenciar o empréstimo dos equipamentos aos alunos (FERREIRA et al., 2008). E diante da atual situação de distanciamento por conta do COVID-19, torna-se inviável o manuseio dos equipamentos e da estrutura física.

O alto custo geralmente faz com que o número de instrumentos seja insuficiente para atender todas as turmas. Além do mais, a flexibilidade desses laboratórios é limitada, pois os instrumentos utilizados não permitem aos usuários expandi-los ou personalizar seus parâmetros de medida, como resolução, precisão e taxa de atualização, de acordo com a aplicação requerida.

A distância que separa a prática de novas tecnologias no mercado de trabalho e no universo acadêmico pode ser medida pela vivência, que o estudante de engenharia passa em atividades laboratoriais com recursos tecnológicos avançados e aulas práticas em áreas tão diversas como aquelas, em que poderá atuar profissionalmente. As facilidades advindas da utilização de sistemas aquisição e tratamento dados por meio do uso de hardware e software apropriado levam a uma presença cada vez maior destas ferramentas associadas a diversos tipos de sistemas desenvolvidos pelo homem. Os sistemas ligados à área de energia elétrica permitem aos usuários destes tipos de ferramentas facilitar o seu monitoramento, operação e manutenção.

Para a utilização de recursos no ensino, é necessário ter clara a abordagem educacional que será utilizada, definindo o papel destes dentro da sala de aula. Desta forma, aprendizagem pode ser encarada a partir de duas visões educacionais: a promoção do ensino ou a construção do conhecimento (VALENTE, 1997).

Dessa forma, e fazendo uso dos conhecimentos de Cálculo, Engenharia e Sustentabilidade, que o trabalho tem por objetivo apresentar algumas de suas potencialidades aplicações do software LabVIEW da National Instruments, aplicado em experiências ligadas à área de sistemas de energia elétrica associado a geração de energia eólica, de tal maneira que atendam às necessidades das aulas experimentais dos cursos de engenharia elétrica como ferramenta de apoio ao ensino remoto. Para tanto, utilizando a programação com software LabVIEW, propõe-se o desenvolvimento de uma plataforma com instrumentos virtuais, para captação do vento, da potência, energia, coeficiente de rendimento, entre outros.

O intuito da solução desenvolvida é fornecer aos alunos da disciplina do curso de engenharia elétrica uma plataforma flexível, na qual as aplicações de cada instrumento virtual possam ser executadas de acordo com a necessidade de uma aula prática. 


\section{REVISÃO BIBLIOGRÁFICA}

Para a estruturação do presente trabalho torna-se necessário o conhecimento de alguns conceitos a respeito de laboratórios de ensino em engenharia, instrumentação virtual, aquisição de dados e softwares para virtualização de instrumentos, e definições sobre a geração de energia eólica

\subsection{Laboratórios de Ensino em Engenharia}

As atividades realizadas em laboratórios de ensino nos cursos superiores de engenharia são momentos importantes e oportunos para os alunos colocarem em prática o conteúdo abordado na teoria. Nelas, são demonstrados fenômenos, coleta de dados, testes, hipóteses, enfim, desenvolvem habilidades de observação ou medida, adquirindo familiaridade com os instrumentos e aparatos de medida (RANGEL et al., 2014).

Constatada a importância dos laboratórios experimentais no ensino de engenharia, percebe-se que eles têm sido grandes aliados dos profissionais e pesquisadores ao proporcionarem ambientes adequados para a aplicação das técnicas especificas. Segundo o estudo de Morais et al. (2014), os laboratórios experimentais em engenharia vêm evoluindo nas últimas décadas.

Com a evolução dos equipamentos de informática, houve nos últimos anos uma forte integração entre os componentes físicos dos laboratórios e as ferramentas de informática, como os conversores analógicos/digitais e sistemas de aquisição de dados. Os chamados laboratórios de terceira geração introduziram o conceito de instrumentação virtual, dispensando o uso de muitos instrumentos analógicos e/ou digitais específicos. O LabVIEW é uma dessas tecnologias, no qual é uma linguagem apropriada para o desenvolvimento de interfaces com o usuário, interagindo com o programador por meio de duas telas separadas: o painel frontal e o diagrama de blocos.

No painel frontal, os botões, os indicadores e os gráficos podem ser alcançados para controle direto do usuário. Já no diagrama de blocos, o fluxo de dados e as funções de controle podem ser desenvolvidos através do código fonte gráfico que define a funcionalidade do VI (Visual Instruments).

O painel frontal é parte do $\mathrm{VI}$, que define a relação de usuário. Esta interface com o usuário é desenvolvida por meio de controles e indicadores, que são os terminais interativos de entrada e de saída do VI, respectivamente. Os controles são botões, chaves seletoras, e outros mecanismos de entrada que simulam mecanismos de entrada no instrumento virtual, fornecendo dados ao diagrama de blocos. O diagrama de blocos é desenvolvido através de representações gráficas de funções para controlar os objetos do painel frontal. As representações gráficas das funções podem ser operações matemáticas, lógicas ou estruturas de programação (while loop, for loop, case structure, etc.) e os objetos do painel frontal são os terminais presentes no diagrama de blocos dos respectivos controles e indicadores.

A realização das experiências fica facilitada visto que as medições são realizadas de maneira automática, permitindo aos alunos concentrarem-se na análise dos conceitos vistos em sala de aula.

\subsection{Geração Eólica}

A tecnologia avança a largos passos, o desenvolvimento econômico encontra-se acima de qualquer coisa e consequentemente, a demanda por energia elétrica é cada vez 
maior. Portanto, torna-se necessário que o ser humano busque novas fontes de energia renováveis e não poluentes, para que haja uma combinação rentável entre proteção do meio ambiente e desenvolvimento econômico. Tendo isso em mente, a energia eólica representa uma excelente fonte renovável para produção de energia elétrica e apresenta um baixo impacto ambiental, além de seus custos de instalação e manutenção diminuírem a cada ano, o que a torna rentável ao longo do tempo.

A geração de energias renováveis através de aerogeradores, ocorrem com a utilização dos ventos que consistem em diferenciais de pressão. Esse modo de conversão de energias, utiliza de princípios físicos para a obtenção de eletricidade. A captação do vento através das pás, possibilita a rotação de um rotor que está acoplado em um gerador, e a tensão gerada é enviada até uma central de energia utilizada como complemento dos outros meios de geração, visto que depender somente dessa fonte de energia ainda é arriscado por ser necessária a presença contínua de ventos (CUSTÓDIO, 2009).

O potencial eólico disponível pode ser definido como a energia cinética que passa através das pás do gerador em um determinado tempo. Então a energia cinética da massa de ar pode ser expressa pela Equação (1):

$$
E_{c}=\frac{m v^{2}}{2}
$$

$\mathbf{m}$ é a massa de ar que flui através das pás do gerador e $\mathbf{v}$ é a velocidade do vento em $\mathrm{m} / \mathrm{s}$. A vazão do vento pode ser definida através do fluxo de massa expresso pela Equação (2) em $\mathrm{kg} / \mathrm{s}$ :

$$
\dot{m}=\rho A v
$$

$\rho$ é a massa específica do ar, A é a área de varredura das pás e v a velocidade do vento que flui pela seção transversal das pás. O potencial eólico pode ser expresso pela diferenciação da energia pela unidade de tempo

$$
P=\frac{\rho \dot{m} v^{2}}{2}
$$

Reescrevendo e unindo as Equações (2) e (3) temos a Equação (4) que expressa a potência relacionando a massa específica, área da seção das pás do gerador e a velocidade do vento que escoa pelo gerador (CUSTÓDIO, 2009):

$$
P=\frac{\rho A v^{3}}{2}
$$

Com a Equação (4) é possível estimar a potência disponível em Watts, em determinada seção transversal na qual o vento irá fluir.

Os aerogeradores são formados por um conjunto de peças e outros pequenos subconjuntos com a intenção de converter a energia cinética dos ventos em energia elétrica. O elemento mais importante de um aerogerador são as pás da turbina ou rotor logo após vem o multiplicador mecânico e o gerador elétrico que converte energia mecânica em elétrica.

A orientação do eixo rotacional determina a primeira classificação da turbina eólica. Uma turbina com um eixo montado horizontalmente paralelamente ao solo é conhecida como uma turbina eólica de eixo horizontal. Uma turbina eólica de eixo vertical tem o seu eixo normal ao solo (SCHUBEL; CROSSLEY, 2012). 
Segundo Bak (2013) os aerogeradores além de serem divididos entre verticais e horizontais, complementa categorizando como baixa velocidade rotacional, devido ao alto torque e de alta velocidade rotacional que é mais comum para geração de energia elétrica.

Figura 1: Diferentes tipos de aerogeradores
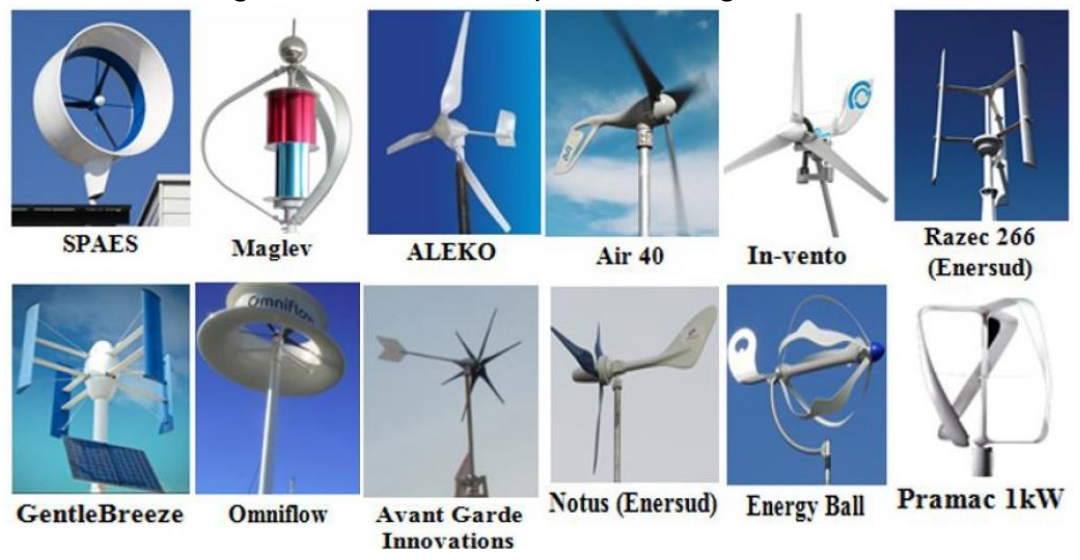

Fonte: Autor desconhecido

Segundo Miranda (2014), as primeiras turbinas eólicas de geração de energia elétrica, operavam com velocidades fixas ou quase constantes, tendo a velocidade do rotor fixa e determinada pela frequência da rede, porém como o vento é um fator muito imprevisível, em determinados momentos, as turbinas tinham de ser desconectadas da rede, devido aos problemas que causavam. Conforme recordado por Blaabjerg et al., (2004), a geração de energia elétrica das primeiras turbinas eólicas era através de geradores de indução de gaiola de esquilo, diretamente conectado à rede, desta forma a transferência dos pulsos mecânicos gerados pelos ventos, são transferidos para rede elétrica. $\mathrm{O}$ autor vê a eletrônica de potência como a tecnologia-chave para tornar a energia eólica, uma fonte ativa de energia.

A turbina eólica equipada com o gerador de indução de dupla alimentação, conforme apresenta a Figura 2 passa a ter seu campo eletromagnético induzido externamente por um conversor CA-CC-CA como forma de controle permitindo a variação da velocidade $e$ possuindo um valor de custo competitivo, porém a desvantagem está relacionada com a necessidade da caixa de engrenagem (gearbox) e a necessidade da rede elétrica para operação. Vale ressaltar que este tipo de turbina também pode possuir controle de ângulo de pá, melhorando ainda mais o controle sobre a turbina.

Figura 2: Turbina com velocidade variável

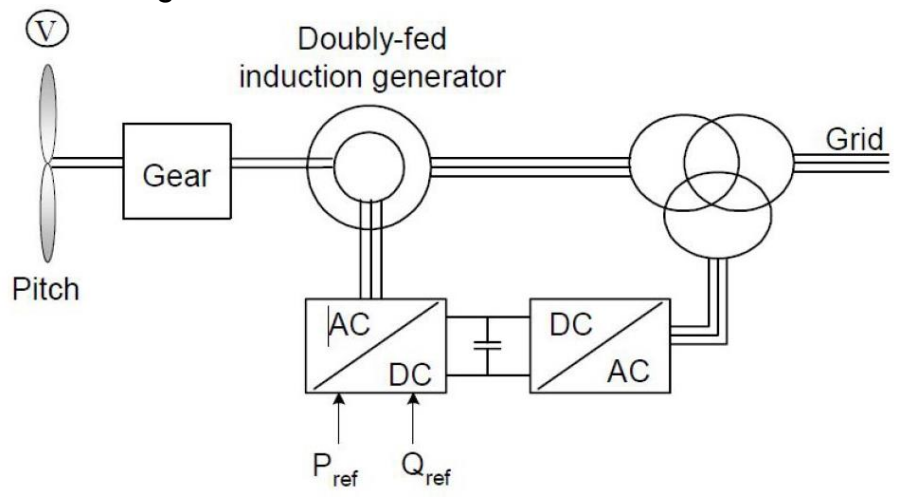

Fonte: Blaabjerg et al., (2004) 
A energia gerada pode ser manipulada com o intuito de atender determinadas necessidades, um exemplo é a utilização de transformadores para provocar uma elevação ou diminuição no valor da tensão gerada. Este tipo de transformação é utilizado para transmissão de eletricidade a longas distâncias, elevando-se a tensão, tem-se uma menor corrente e de acordo com a lei de Ohm, a corrente é inversamente proporcional a tensão, o que implicaria em uma menor secção transversal do condutor, reduzindo os gastos com material.

\section{UTILIZANDO O LABVIEW NA GERAÇÃO EÓLICA}

Um projeto de forma genérica geralmente possui diversas etapas e geralmente utiliza pessoas, ferramentas e ou softwares diferentes em cada etapa, que são ferramentas que podem ser utilizadas individualmente, ou podem ser utilizadas juntas e somadas a metodologia do projeto e suas fases.

A turbina eólica capta a energia cinética realizada através do movimento das pás do aerogerador. A equação que extrai a potência $P_{0}$ do vento através das pás do aerogerador é a diferença entre a velocidade da frente e atrás das pás, que é dada pela equação:

$$
P_{0}=\frac{1}{2} R_{v}\left(V^{2}-V_{0}^{2}\right)
$$

onde $R_{v}$ é a vazão volumétrica da massa de ar por segundo e $V$ para $V_{0}$ é a velocidade do ar é descontinua no plano das pás do rotor.

Relacionando o fluxo de massa de ar que passa através das pás tem se potência $P_{0}$ extraída pelo rotor:

$$
P_{0}=\frac{1}{2} \rho A V^{3} C_{p}
$$

onde $C_{p}$ é o coeficiente de potência. A lei de Betz ou coeficiente de potência desenvolvido pelo físico alemão Albert Betz em 1919 determina que somente 59,3\% da energia cinética do vento pode ser convertida a energia mecânica.

$\mathrm{Na}$ Figura 3 é apresentado o painel frontal do modelo da turbina eólica, onde os dados são simulados e exibidos para uma metodologia manual ou automática. O modelo completo do sistema é um somatório de outros modelos menores e responsáveis cada um por uma área da turbina.

Figura 3: Painel frontal da simulação da Turbina Eólica

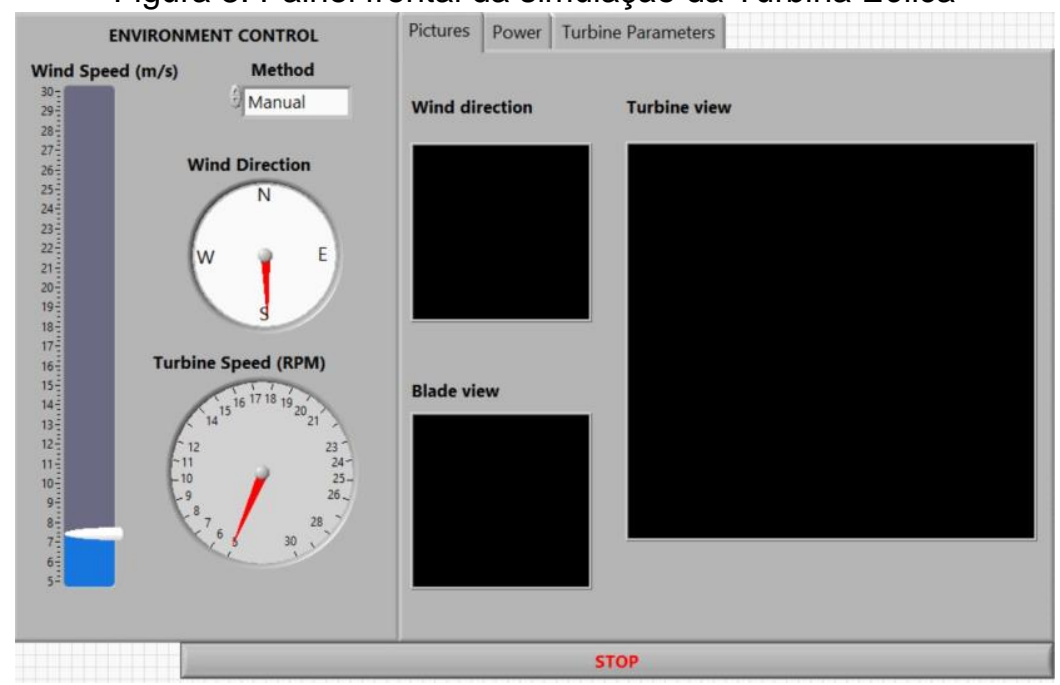

Fonte: Autor 
Nesse painel é possível verificar a direção do vento, a lâmina, ou também identificado de pá, o modelo da turbina eólica. Além dessas informações, é possível analisar a potência gerada e energia gerada, e potência do vento.

Para mais informações, é possível observar as formas de onda dos parâmetros das turbinas, como: velocidade do rotor, ângulo de ataque da pá $(\lambda)$ e coeficiente de potência.

O sistema de yaw é, basicamente, utilizado para otimizar a absorção da energia dos ventos através do posicionamento da turbina na direção do fluxo de vento. São motores elétricos que giram a turbina em um eixo vertical de forma a apontar sua face em direção ao vento. O sistema ainda possui um sistema de freios para manter a posição definida da turbina. Desta forma, foi projetado e simulado em 3D para diversas posições o sistema yaw, conforme Figura 4.

Figura 4: Sistema Yaw e o ângulo de Pitch da Turbina Eólica, para diversas posições
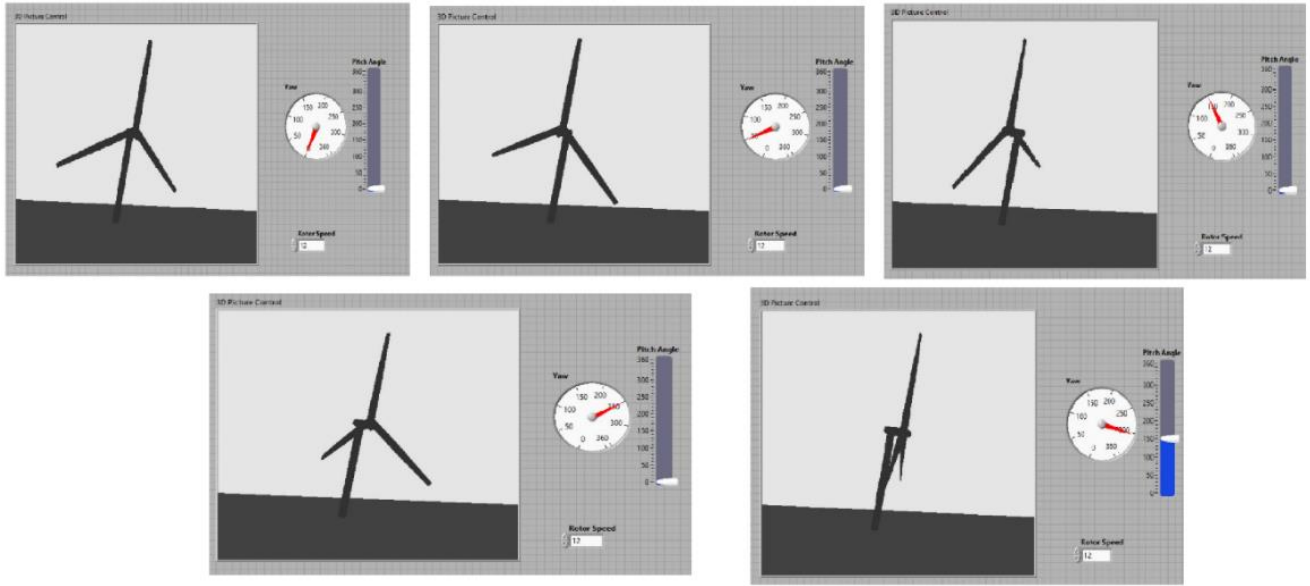

Fonte: Autor

Os sistemas de pitch e yaw de uma turbina eólica requerem algum tipo de sensor que meça a velocidade do vento, no caso do pitch, e a direção do vento, para yaw, para que possam funcionar adequadamente. Seus sistemas de controle atuam através da referência recebida por um equipamento de medição chamado de anemômetro. Em geradores com velocidade variável, as medições de intensidade de vento também são necessárias para controlar a velocidade rotacional da máquina e assim otimizar a extração de potência dos ventos.

O bloco da turbina eólica, conforme Figura 5 recebe um valor de velocidade de vento e converte para uma potência mecânica, que neste caso irá para uma caixa de redução, identificado como caixa de engrenagem.

Figura 5: Turbina Eólica

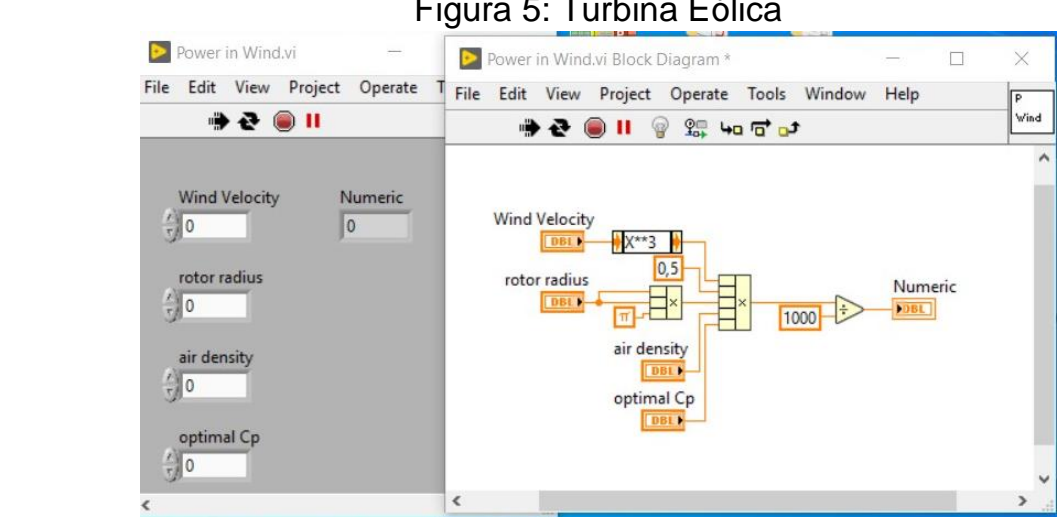

Fonte: Autor 
O sistema de transmissão ou gearbox, termo mais comum na literatura americana é a caixa de redução da turbina, responsável por transformar a velocidade e o torque disponível nas pás, para uma velocidade e torque compatível com os necessários para o gerador funcionar. Porém existem geradores com acoplamento direto entre as pás e o gerador, então nestes casos, seria retirado o bloco de caixa de redução.

Figura 6:Caixa de engrenagem

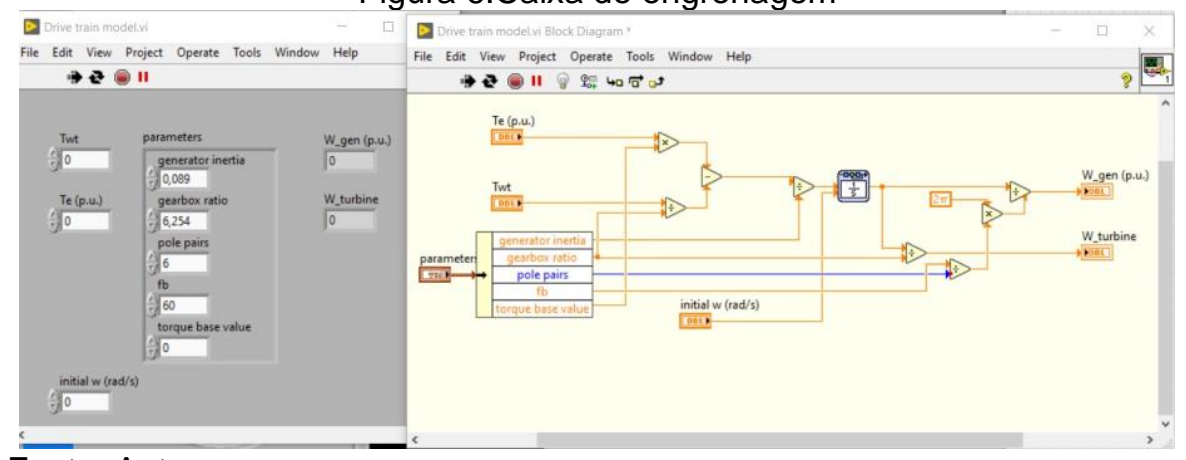

Fonte: Autor

O modelo da rede disposto na Figura 7 simula a concessionária de energia elétrica, no qual é formado por onda similar ao formato gerado pelos geradores de energia de fontes convencionais. Neste modelo a rede é utilizado para induzir o gerador do aerogerador e também serve como valor de referência para o controlador.

Figura 7:Potência na Rede

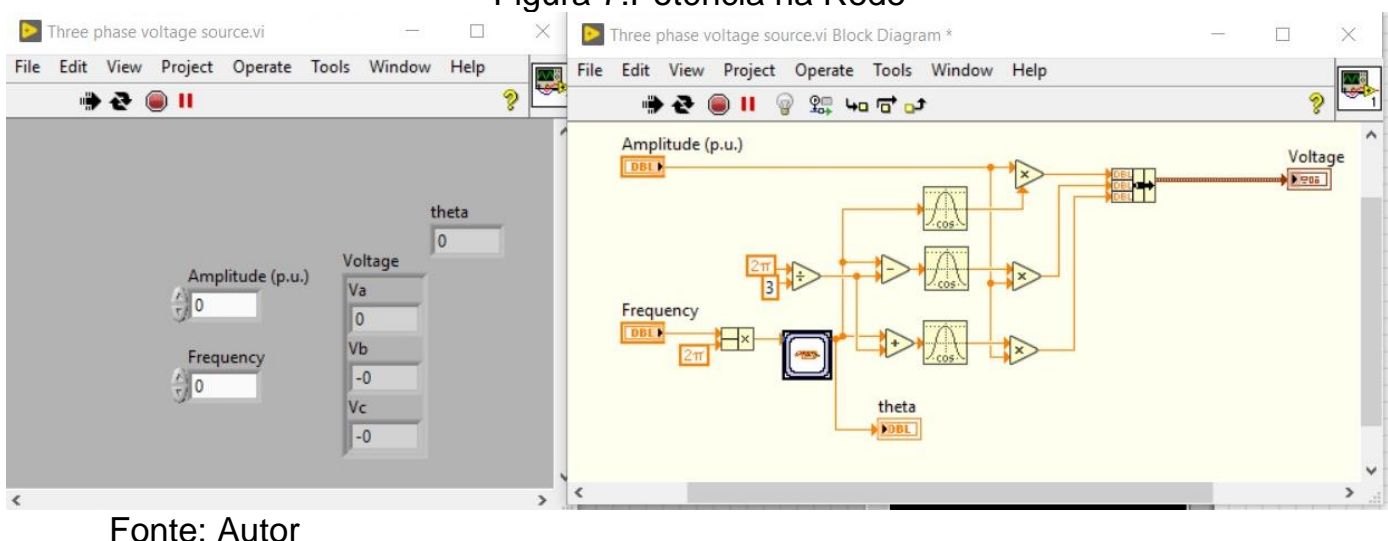

A Figura 8 tem por objetivo controlar todo o sistema da turbina, recebendo os valores de referência, como velocidade do vento, velocidade da redução, velocidade do gerador, ângulo do gerador e seus valores de corrente.

O controlador atua principalmente sobre o ângulo das pás, pois desta forma tem a capacidade de frear ou acelerar a turbina. O controle do ângulo das pás apesar de ser importante para a geração, é muito mais importante para a segurança da turbina, pois no caso de ventos acima do limite máximo, utiliza essa função para desacelerar a turbina eólica, com o a função de proteção. 
Figura 8:Controle do Sistema DFIG

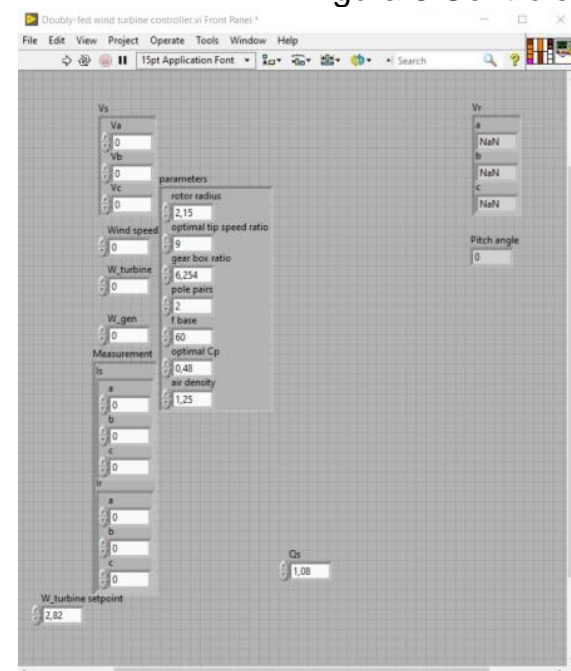

䀧要

Fonte: Autor

É último passo para geração eólica, é o modelo dentro do diagrama de blocos responsável por fazer a conversão da energia mecânica para energia elétrica.

Figura 8:Gerador de Indução de Dupla Alimentação

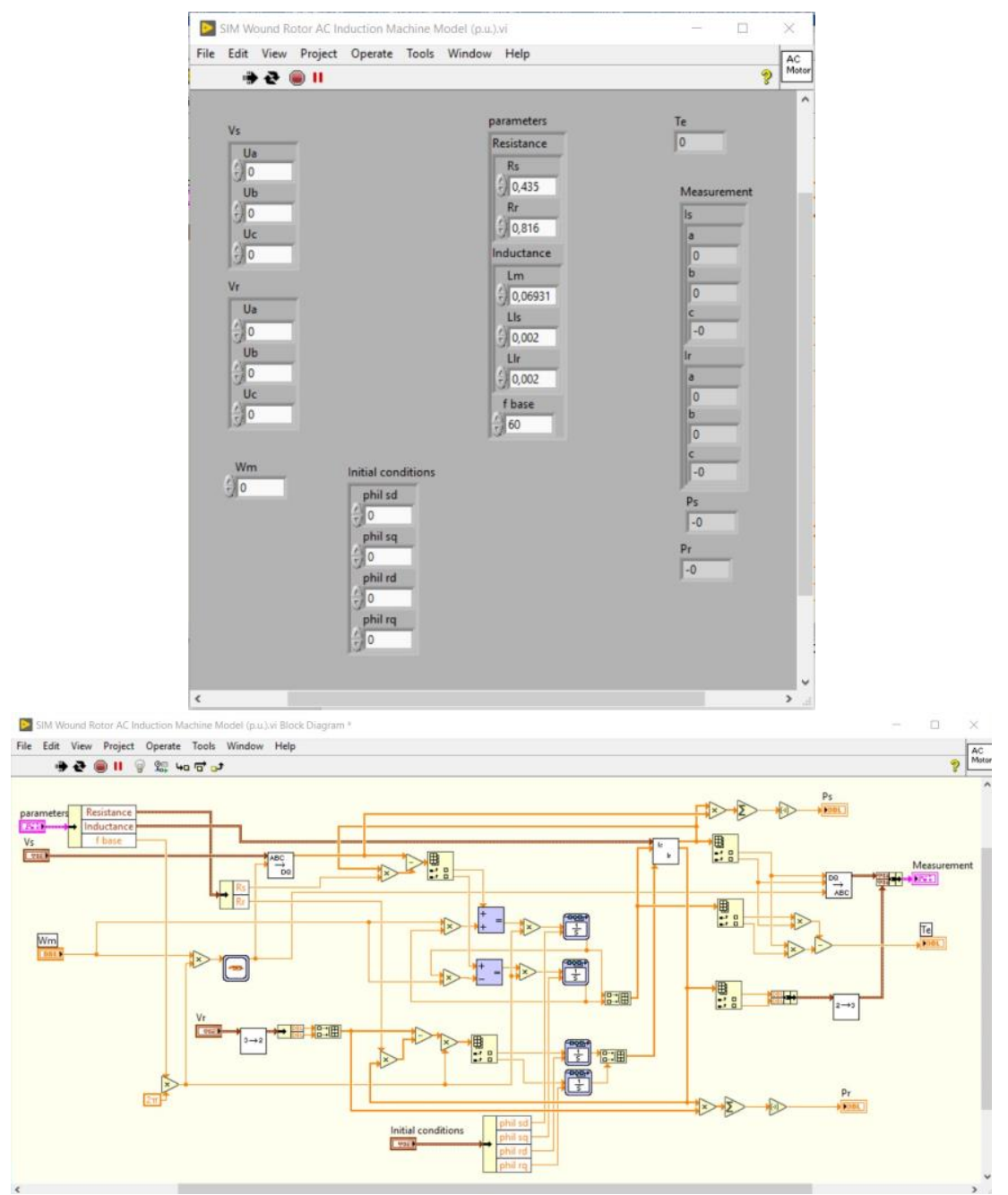

Fonte: Autor

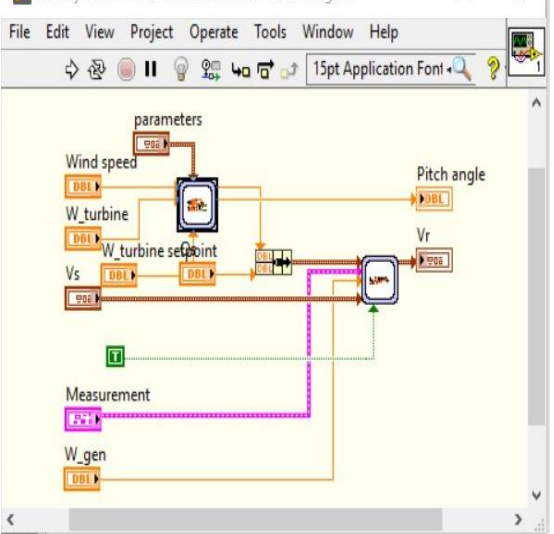




\section{$4 \quad$ RESULTADOS E DISCUSSÕES}

Após desenvolvimento na plataforma do Labview o sistema de Geração Eólica, foi possível verificar os resultados.

Para as primeiras simulações, foram realizadas no método manual. E como resultado, deu se a direção do vento ao sul, com uma velocidade média de $17,5 \mathrm{~m} / \mathrm{s}$. A turbina modelada foi de eixo horizontal, com velocidade rotacional de 26rpm.

Figura 9:Turbina Eólica no método manual
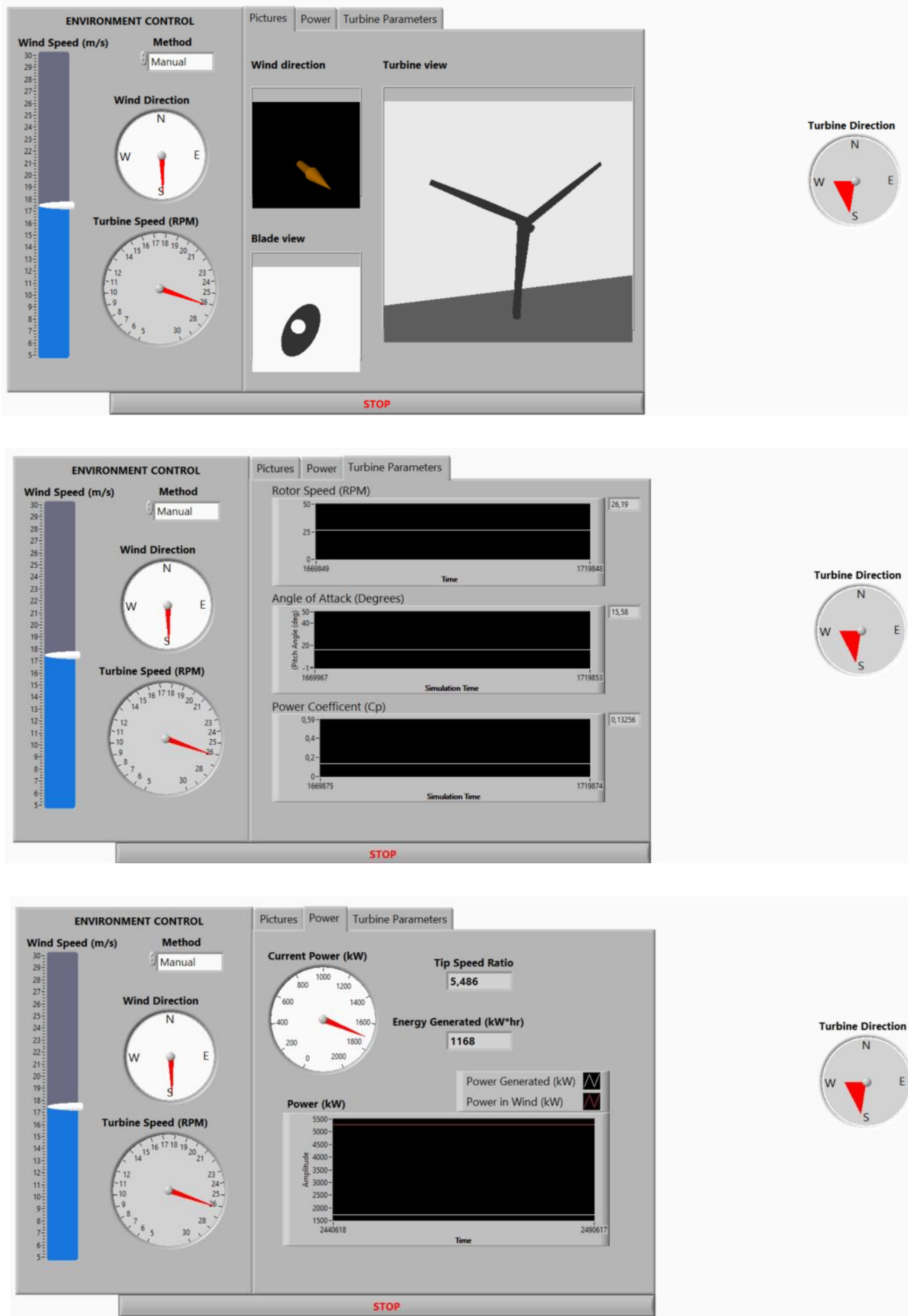

Fonte: Autor 
No modo automático, a velocidade do vento varia de acordo com o ângulo de pitch. $O$ vento e a turbina foram direcionados ao norte, com velocidade rotacional de $26 \mathrm{rpm}$. Com a variação da velocidade de $10 \mathrm{~m} / \mathrm{s}$ obteve como resultado para coeficiente de potência 0,4 e $0^{\circ}$ de ângulo de pitch.

Figura 10:Turbina Eólica no método automático
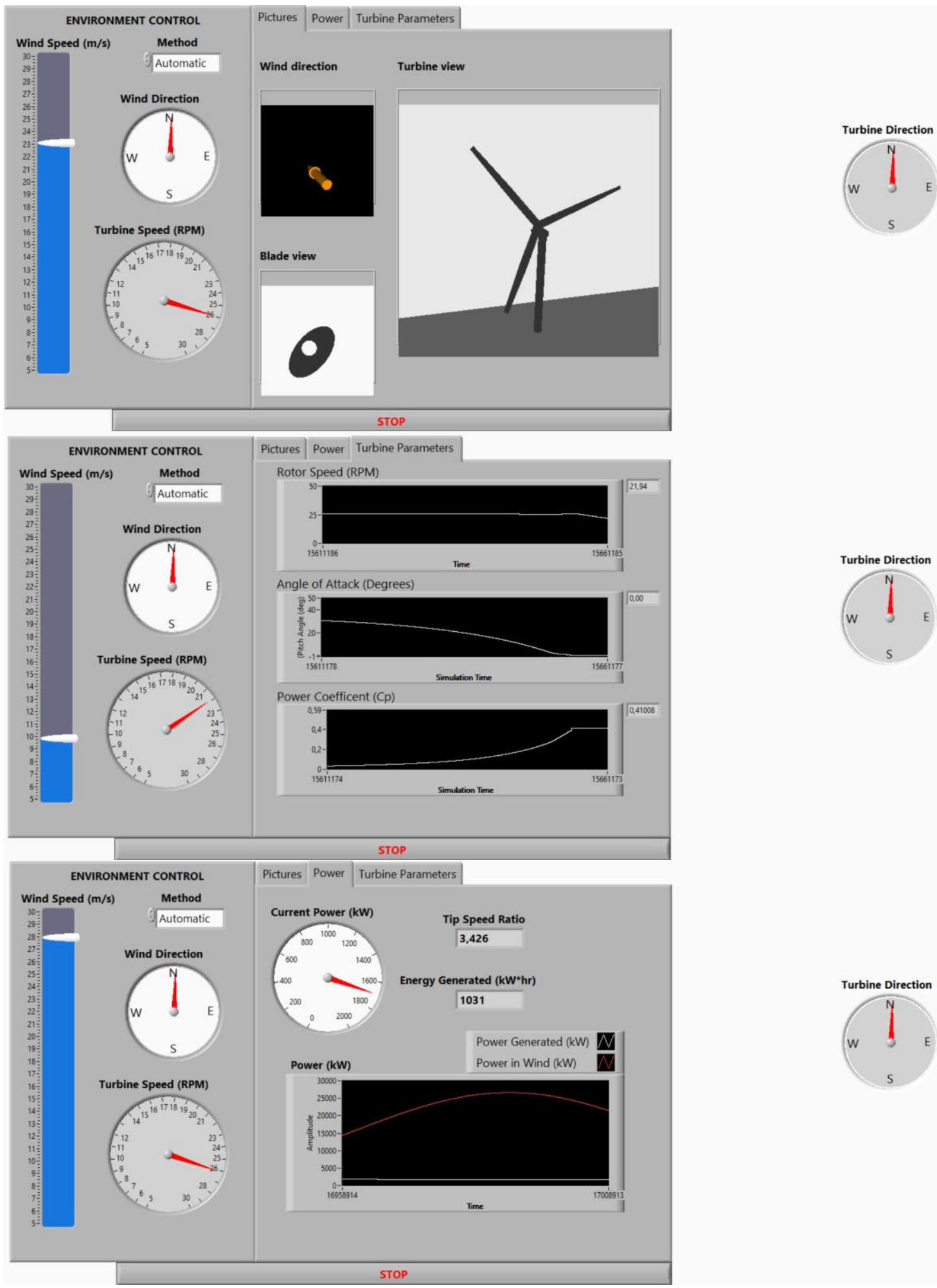

Fonte: Autor 


\section{CONCLUSÃO}

Este trabalho permitiu mostrar os resultados de um projeto no qual foi utilizado o software Labview para automatizar a aquisição, tratamento, visualização e armazenamento de sinais de geração eólica. É possível citar como vantagens do uso desta ferramenta de aquisição e tratamento de dados, a possibilidade de monitorar muitos pontos simultaneamente e também a possibilidade de gravar os dados em arquivo.

Conforme visto os resultados e discussões apresenta que a simulação é uma ferramenta que permite a economia de recursos financeiros quando é necessário efetuar vários ensaios, pois o custo de cada ensaio torna-se financeiramente alto.

Este trabalho mostrou também que é possível trabalhar com práticas laboratoriais mesmo não tendo um espaço físico, servindo como alternativa para a atual situação em que o mundo se encontra diante do distanciamento social, decorrente do COVID-19.

O importante é que os novos recursos, como o computador, não sejam usados apenas como instrumentos, mas se tornem capazes de desencadear transformações estruturais na velha escola.

\section{REFERÊNCIAS}

AGILENT TECHNOLOGIES. Osciloscópios na área educacional. Fev. 2012. Disponível em: <http://literature.cdn.keysight.com/litweb/pdf/5990-9166PTBR.pdf>. Acesso em 20 abril 2021.

BAK, C. Aerodynamic design of wind turbine rotors. [s.I.] Woodhead Publishing Limited, 2013. v. 1

BLAABJERG, F. et al. Power Converters and Control of Renewable Energy Systems, 2004.

CUSTÓDIO, Ronaldo dos Santos. Energia Eólica: Para a produção de energia elétrica. Rio de Janeiro: Memória da Eletricidade, 2009. 280 p.

MORAIS, Érica V.; OLIVEIRA, Luís C. O.; OLIVEIRA, Rodrigo A. N.; BOVOLATO, Luiz F.; ORTEGA, Aleciana V. Evolução dos laboratórios experimentais de engenharia elétrica: premissas para o ensino à distância e pesquisa coorporativa. Revista Visão Universitária 2014.

Disponível

em: <http://www.visaouniversitaria.com.br/ojs/index.php/home/article/view/27/18>. Acesso em: 15 abril. 2021.

FERREIRA, Rafael F.; LINS, Zanoni D.; CAVALCANTI, Marcelo C. Virtualização de instrumentos industriais utilizando o LabVIEW. Dept. de Eng. Elétrica e Sistemas de Potência, UFPE - Universidade Federal de Pernambuco. VIII Conferência Internacional de Aplicações Industriais - Induscon. Ago. 2008. Disponível em: <https://www.researchgate.net/publication/267965547_VIRTUALIZACAO_DE_INSTRUME NTOS_INDUSTRIAIS_UTILIZANDO_O_LABVIEW>. Acesso em: 20 abril 2021.

MIRANDA, P. L. K. DE. Controle de geradores de ímãs permanentes com fem trapezoidal aplicado em aerogeradores sob condições de afundamento de tensão da rede elétrica: falhas simétricas, 2014.

RANGEL, Silvana V. D.; SILVA, Marcos B. C.; RANGEL, Luís A. D.; SOARES, Rosana A. R. Segurança em práticas de ensino em Laboratórios de Engenharia. Revista Práxis, ano IV, n. 12, Dez. 2014. Disponível em: <http://web.unifoa.edu.br/praxis/numeros/12/105-116.pdf>. Acesso em: 12 abril. 2021.

SCHUBEL, P. J.; CROSSLEY, R. J. Wind turbine blade design. Energies, v. 5, n. 9, p. 3425-3449, 2012. 
VALENTE, J. A. O uso inteligente do computador na educação. Pátio - Revista Pedagógica, Porto Alegre, v. 1, n. 1, p. 19-21, mai. 1997.

\title{
WIND POWER GENERATION USING THE LABVIEW PLATFORM
}

\begin{abstract}
This article aims to present some potential applications of the LabVIEW software from National Instruments, as a practical learning tool disassociated from the physical laboratory, applied in experiments related to the area of electric power systems as a tool to support remote teaching in wind generation. It is known that the process of generating energy through wind turbines is complex, given its components and how they interact as a whole, presenting the advantages and disadvantages of this means of generation. With the aid of LabVIEW, wind data and wind speed measurement were obtained through its modeling. This program allows access to the experimental assembly of the mini energy system by the computer installed on the laboratory bench, also allowing students to monitor and control the experiment from their own computers, visualizing and reinforcing in the laboratory, the concepts seen in theory.
\end{abstract}

Keywords: wind, wind turbine, power coefficient, renewable energy 